\title{
RECURRENCE MARKING IN AKAN ${ }^{1}$
}

\author{
Nana Aba Appiah Amfo
}

\begin{abstract}
The linguistic phenomenon of recurrence is identified in two aspects; either as a repetition of an action or a restoration to a former state. This paper examines two lexical items, an auxiliary verb san and an adverb (e)bio, which encode this phenomenon in Akan. The recurrence marker san is claimed to be the output of a grammaticalization process which has as its historical input a phonologically identical lexical verb with a restorative meaning. Even though the recurrence marker san is diachronically associated with restoration, its use gives rise to either a restorative or a repetitive assumption, in the form of an implicated premise. This assumption forms part of the context within which the utterance containing san is interpreted. Thus its function coincides with that of $(e) b i o$, except for one particular use of the latter, associated with its occurrence at utterance-initial position. The almost identical functions of these two markers reveal the close conceptual relationship between recurrence of the repetitive and of the restorative type.
\end{abstract}

Keywords: Akan, Grammaticalization, Recurrence, Relevance theory, Implicature.

\section{Introduction}

Linguistic communication of the recurrence of a phenomenon means that a proposition $P$ representing that phenomenon, which was true at time $T_{1}$, is once more true at a later time $\mathrm{T}_{2}$, and there is an intervening period between $\mathrm{T}_{1}$ and $\mathrm{T}_{2}$ when $\mathrm{P}$ is not true. In (1), what the utterance conveys by the use of again could be one of two things. It could be that there was a time in the past that the Dean had been at the place where the utterance was made and that there is going to be a time in the future that he will be there. On the other hand, if the Dean was present at the time (1) was uttered, then what again conveys is that s/he will be going away and then return at a later point. The common point is that in between the two events there is a period during which the Dean is not present at the place where the utterance was made.

1 I am grateful to Stella Boateng and Thorstein Fretheim for earlier collaborative work which inspired this paper. I owe thanks to Thorstein Fretheim, Kweku Osam, and an anonymous reviewer for helpful comments. An earlier version of this paper was presented at the Department of Linguistics Seminar Series at Legon. I am grateful to that audience particularly Kofi K. Saah, Kofi Agyekum and Marcy Esther Kropp Dakubu. Usual disclaimers apply. 
(1) The Dean will be here again.

The linguistic phenomenon of recurrence can be conceived in two different ways. It can be conceived as repetition of an action or restoration to a former state. However, as this paper illustrates, in accordance with Amfo et al (2004), these two aspects are not mutually exclusive, they can actually coincide in a single utterance. Returning to example (1), this utterance in a certain context could mean that the Dean had been visiting the place denoted by the deictic expression here some time before (1) was uttered and intends to make another visit (for the second, or maybe the third or fourth time) to the place. The reference is then to the repetition of a specific event. In another context, the place referred to could be the Dean's old office, which he vacated at some point in time, but to which he is now returning. Then a restorative interpretation becomes salient, in the sense that the Dean is being returned to a former (original) position. The process of restoration implies that the Dean needs to repeat an action of moving into the same room and making it his own office. Restoration entails repetition in this case and as a result one can talk of the two recurrence senses of again as coinciding in (1), though the restoration sense is more salient, partly because the predicate be here does not refer explicitly to any action on the part of the subject referent. More so, the absence of an activity verb suppresses a repetitive interpretation.

This paper examines how this phenomenon is manifest in a Niger-Congo (Kwa branch) language, Akan. In this language, the recurrence phenomenon is encoded by means of two lexical items, san and (e)bio ${ }^{2}$. San as a recurrence marker appears to be the result of a grammaticalization process, which has as its historical input a main lexical verb, which is identical in form to the recurrence marker and has the conceptual meaning of 'to return'. As a recurrence marker, this form appears as a close syntactic companion of a main verb (or series of main verbs in the case of serial verb constructions). The other recurrence marker bio is not an accompaniment of a lexical verb but an independent adverb with the syntactic liberty to occur utterance-initially, in addition to its more frequent post VP position. This paper demonstrates that in spite of the syntactic and historical differences between san and bio, these two markers function similarly, except for one function associated with bio, obviously triggered by its relative syntactic freedom. They are both procedural markers of recurrence, in that their function is to indicate to the interlocutor to include, in the interpretation process, the contextual assumption that the proposition expressed by the utterance in which they are contained represents a state of affairs which existed at least once before.

\section{Relevance theory and grammaticalization}

The two lexical items under consideration in this paper are analysed within a cognitively based inferential theory of communication - Relevance Theory, henceforth RT (Sperber and Wilson 1986, 1995). RT draws inspiration from the Gricean inferential theory of meaning (Grice 1975), although the interpretation processes for these two theories differ significantly. For Grice, if any communicated information is not due to the linguistic meaning of an utterance, it is due to an implicature, conventional or

\footnotetext{
${ }^{2}$ In speech and even in writing, ebio is very often represented as bio.
} 
conversational. On the other hand, relevance theorists consider the inferential process to include derivation of explicatures as well as implicatures.

An explicature, according to Carston (2002: 377), is "an ostensively communicated assumption which is inferentially developed from one of the incomplete conceptual representations (logical forms) encoded by the utterance". Deriving explicatures involves decoding of linguistic material as well as pragmatic processes such as disambiguation, saturation, free enrichment and ad hoc concept constructions. Some aspects of saturation such as reference assignment involve finding values for overt indexicals like pronominals, while others involve 'completion' processes for utterances which do not have a complete propositional form and contain so-called covert indexicals. The form too young in (2) will have to be saturated to something like "too young to marry the speaker" in order for that utterance to be fully propositional, hence relevant.

(2) Fred is too young.

Recanati (2004) refers to the pragmatic phenomenon of saturation as bottom-up linguistically controlled pragmatic processes. On the other hand, top-down pragmatically (in contrast to linguistically) controlled pragmatic processes, often referred to as free enrichment, are also obligatory processes for utterances like the one in (3).

(3) Peter has eaten breakfast.

Unless (3) is enriched to express a proposition like 'Peter has eaten breakfast on the day (3) was uttered', it will not be optimally relevant in that it will only be expressing a trivial truth which will be of no interest to any interlocutor. Notice that the enrichment required in (3) is not triggered by any linguistic element in that utterance.

Ad hoc concept construction is another pragmatic process involved in the derivation of explicatures. Lexical concepts which are used in utterances are very often pragmatically adjusted through the process of narrowing or loosening in the interpretation process. In (4), what the interlocutor takes the speaker to have expressed, regarding the description of Lilian's face, is not the encoded concept of square (four equal sides with four right angles) but a wider concept which shares some features with the encoded concept.

\section{(4) Lilian has a square face.}

An implicature, on the other hand, is a deliberately communicated assumption which is not an explicature, that is, it is "a communicated assumption which is derived solely via processes of pragmatic inference", (Carston 2002: 377). In contrast to explicatures, implicatures are not 'developments' of logical forms. That not withstanding, as this paper demonstrates using san and bio, certain linguistic forms that appear in the logical form may trigger certain assumptions which act as implicated premises in the inferential process.

Relevance theory distinguishes two kinds of implicatures: Implicated premises and implicated conclusions. Implicated premises form part of the set of contextual assumptions employed in the interpretation process and implicated conclusions belong 
to the set of contextual effects derived as a result of combining a given utterance with contextual assumptions. The following examples (5) and (6), adapted from Carston (2002: 135) illustrate the distinction between implicated premises and implicated conclusions.

(5) A: Let's go to a movie. I've heard Sense and Sensibility is good. Are you interested in seeing it?

B: Costume dramas are usually boring.

(6) a. Sense and Sensibility is a costume drama.

b. Sense and Sensibility is likely to be boring.

c. B isn't interested in seeing Sense and Sensibility.

In interpreting B's utterance in (5), A avails herself of the implicated premise in (6a), which is derived based on the assumption that B's utterance is indeed intended as an answer to A's question. The implicated premise is an assumption from which the implicated conclusions in (6b) and (6c) follow deductively.

The successful retrieval of the intended message of an utterance, whether as an explicature or an implicature, depends on the ability of the interlocutor to combine the given utterance with contextual assumptions to yield adequate contextual (or cognitive) effects. The central claim of RT which is expressed in the communicative principle of relevance ${ }^{3}$ is that the expectation of relevance raised by an ostensively communicated stimulus is high enough to be worth the interlocutor's attention and processing. An utterance is relevant enough when it combines with contextual assumptions (background information) to yield adequate contextual effects. The contextual assumptions form part of the context within which the utterance is interpreted. Context is defined psychologically by Sperber and Wilson as "a subset of the hearer's assumptions about the world". All the linguistic, social, cultural, ethnographic and participant variables which affect context do so via the assumptions that the interlocutor uses in an interpretation process. Access to the appropriate context is crucial and thus following the principle of optimal relevance ${ }^{4}$, the speaker may highlight aspects of the context by the use of certain linguistic signals. The two recurrence markers discussed in this paper are used to indicate to the interlocutor that a particular contextual assumption in the form of an implicated premise is crucial in the inferential process. The assumption is that there is a repetition of an action denoted by the main verb or a restoration of a state of affairs also denoted by the main verb used. The explicature of B's response in (7) is that 'Opoku is eating', at the time the utterance was made. The use of either of the linguistic expressions san or bio, triggers the implicated premise that 'Opoku was eating a fairly short time ago', during an earlier contextually determined period before (7) was uttered. This implicated premise may then form part of a set of

\footnotetext{
${ }^{3}$ The communicative principle of relevance states that "every ostensive stimulus conveys a presumption of its own optimal relevance" (Wilson and Sperber 2004: 612).

${ }^{4}$ The presumption of optimal relevance (Sperber and Wilson 1995; Wilson and Sperber 2004) comes in two parts. The interlocutor can expect the stimulus to be relevant enough to be worth processing. At the same time, the speaker wanting to be understood will make the ostensive stimulus as easy as possible for the interlocutor to understand, within the limits of her (the speaker's) capabilities and preferences.
} 
contextual assumptions, which may lead the interlocutor in the derivation of further implicated conclusions such as 'Opoku is overfeeding himself'.

(7) A: Opoku re-ye den?

Opoku PROG-do what?

'What is Opoku doing?'

B: o-re-san a-didil o-re-didi bio.

He-PROG-return CONS-eat/ he-PROG-eat again.

'He is eating again.'

This aspect of utterance interpretation, which involves the use of certain linguistic items to constrain the context in a way that aids the interlocutor in his inferential processing, is known as encoding of procedural information. It is sometimes contrasted with the encoding of conceptual information which is the input to inferential computations. Words and expressions which are said to encode procedural information contribute to the interpretation process by encouraging the interlocutor to look for certain types of inference relations which further give rise to contextual effects. In other words, these linguistic expressions indicate to the interlocutor how the linguistically encoded concepts of an utterance are expected to be interpreted such that maximum contextual effects are yielded for minimum processing effort. As Carston (2002) puts it, words and expressions of this nature "indicate, guide, constrain or direct the inferential phase of comprehension". Blakemore (1987) introduced this aspect of utterance interpretation by a re-analysis of some of Grice's conventional implicatures as being constraints on implicatures. Further work based on Blakemore's principle of constraints on implicatures (Blass 1990; Wilson and Sperber 1993; a number of papers in Andersen and Fretheim 2000; Blakemore 2002; Amfo 2005) has proved that a number of words (pronouns, function words, particles) in languages across the world, act as constraints not only on implicatures but also on the inferential process which affects the explicit level of utterance interpretation, thereby reducing the effort the interlocutor puts into the pragmatic development of a propositional form from a truth-conditionally underspecified logical form.

The claim of this paper is that san and bio are two such linguistic devices which encode procedural information. By indicating to the interlocutor that the action or situation represented by the proposition expressed existed at least once before, they direct the interlocutor to a particular contextual assumption, in the form of an implicated premise, which is used in the interpretation process. ${ }^{5}$

In accounting for the communication function of the Akan auxiliary $\operatorname{san}^{6}$, one of the two recurrence markers in this paper, the theory of grammaticalization (Hopper and Traugott 1993, 2003) also becomes relevant. Grammaticalization may simply be defined as the development of grammatical units from lexical units, or the advancement

${ }^{5}$ In the case of imperatives their use becomes an instruction to redo something or return something to its original state or position.

${ }^{6}$ The issue of what qualifies to be auxiliary verbs in Akan and other related languages is quite contentious. In fact there is no well-defined class of verbs in Akan which belong to this category. I do not intend to add to this debate at this point, as this is not the focus of this paper. Even though structurally san could well be a serial verb, its semantic contribution to the composite VP is distinct from the two kinds of SVCs identified in the language, integrated SVCs and clause chaining SVCs (cf. Osam 1994). I use the word "auxiliary" in reference to san primarily due to its lack of independent meaning, its apparently reduced verbal morphology and functional distinctness. 
of a less grammatical form to a more grammatical one. Hopper and Traugott (2003: 1) refer to grammaticalization as

\begin{abstract}
that part of the study of language change that is concerned with such questions as how lexical items and constructions come in certain linguistic contexts to serve grammatical functions or how grammatical items develop new grammatical functions.
\end{abstract}

When the function of linguistic items in the interpretation process is being accounted for, it is sometimes, if not always, imperative to consider the syntactic properties as well as the historical origins of the lexical items. One may question the rationale for the combination of RT and the theory of grammaticalization in accounting for a pragmatic marker. Hopper and Traugott attest to the compatibility of these two theories when they refer to the suggestion that "a maxim of Relevance alone, defined in such a way as to include informativeness, is sufficient to account for pragmatic meaning", (Hopper and Traugott 2003: 79). Also, a few other studies have combined these two approaches (Andersen 2000; Nicolle 1998, 2002; Fretheim, Boateng and Vaskó 2002). Nicolle (1998) argues that there is a gradual development from conceptual to procedural encoding of linguistic forms which become grammaticalised, and this is here argued to be the case with san.

\title{
3. San
}

\subsection{San: From main verb to auxiliary}

San exists as two distinct lexical items in Akan. First, it is a lexical verb whose conceptual meaning can be captured as "to return" (intransitive) or "cause to return" (transitive) i.e. to restore somebody/something to a former state or original position.

(8) Kofi re-ko Kumase. o-be-san.

Kofi PROG-go Kumasi. He-FUT-return.

'Kofi is going to Kumasi. He will return (today).'

(9) SE Yawan-tie wo a, me-san no.

CM Yaw NEG-listens you CM, I-return him.

'If Yaw does not listen to you, I will make him return (or I will not let him go).'

The lexical verb san as used in (8) is spatially defined; that is, it has to do with making a turn somewhere in a locality. Its use in (9), depending on how it is interpreted (obviously dependent on the context), may be construed as a metaphorical extension of its spatial conceptual meaning; in that the speaker need not cause a physical return of the object referent in some defined space, she may only need to simply ask the referent of the pronoun no not to embark on a planned journey, which will have to be obeyed as a result of the authority she exerts over the object referent. Again by metaphorical extension of its spatially defined conceptual meaning san can be used to mean 'rescind a decision (to go somewhere)', as illustrated in (10): 
Abena, water PROG-FUT-fall so return.

'Abena, it is about to rain, so don't go (rescind your decision to go).'

Apart from the above-mentioned use(s) of san, it occurs more commonly as an auxiliary in the sense that it appears in the company of one or more fully lexical verbs. These main verbs carry the core (conceptual) meaning in the composite verb phrase, while san directs the addressee to the inference that the proposition expressed represents a situation that was factual at an earlier time as well. In other words san acts as an auxiliary indicating repetition of the action, or restoration of the situation encoded by the main verb. Examples (11) and (12) illustrate this point, where the series of verbs to$o$ ndwom ('sang') in (11) and de ko to-o ('went to put') in (12) denote the actions involved, while san gives rise to the contextual assumption that the action involved is a repetition and a restoration, respectively.

(11) Kofi san to-o ndwom no.

Kofi, return sing-COMPL song DEF.

'Kofi sang the song again.'

(12) Afua san de atere no ko to-o ho.

Afua return take spoon DEF go put-COMPL there.

'Afua brought the spoon back (i. e. returned the spoon to where it was before).'

In contrast to the lexical verb san whose conceptual meaning is defined spatially, the auxiliary san directs the interlocutor to derive an assumption relating to a temporal rather than a spatial return. This is not surprising since time and space relations are inextricably intertwined, as evidenced in the way that a language may use the same linguistic expression to denote a temporal and a spatial meaning. As is well known, meaning transfers from the spatial to the temporal sphere are not uncommon in natural languages. Thus, Lakoff and Johnson (1980) demonstrate how metaphorical concepts derive from spatial orientations. Moreover, many languages use a word with a meaning similar to that of the English adverb back to refer to a temporally prior situation as well as to a local return. Temporal relations are more abstract and less tangible than spatial ones. Movements occur in space (backwards or forwards) along a path but the path can be metaphorically transferred to temporal relations.

Specific procedural indication of recurrence in Akan, made available by the interaction between auxiliary san and the encoded conceptual meaning of the predicate with which it co-occurs, enables an addressee to activate either the assumption that the activity described is a repetition of something that occurred at an earlier time, or the assumption that a state which is the result of an event described represents a return to an original situation or position. Activity verbs, such as $b \mathcal{J}$ ('hit'), to [ade $\mathcal{E}$ ] ('throw'), tia ('to step on') tend to favour an interpretation involving a repetition assumption. When the verb denotes a movement in space like the verb $k J$ ('to go'), as in the sentence Adjoa asan ko sukuu ho ('Adjoa has gone back to the school' or 'Adjoa has gone to the school again'), then repetition and restoration coincide; the result of the act is understood to be a restoration to a former situation, while the extra-linguistic act performed by the agent referred to is understood to be a repetition. 
The auxiliary san is most likely the result of a grammaticalization process whose diachronic input is the full lexical verb san. I have not found proof that use of the auxiliary san is a more recent phenomenon whose existence presupposes a prior temporal stage in which there was a lexical verb san meaning 'to return' but no parallel auxiliary san that indicates an assumption of recurrence. That kind of historical documentation would have been a solid proof of grammaticalization; however, comparing the functions of these two phonologically identical lexical items, one can identify certain processes typical of grammaticalization. Several authors including Hopper and Traugott (1993, 2003), Heine, Claudi and Hünnemeyer (1991) and Nicolle (1998) have noted that when existing forms are assigned new purposes in the grammaticalization process, it is not always the case that there is meaning loss, it could simply be a case of redistribution of meaning. Nicolle (1998) suggests that the meaning shift could be from encoding a concept to encoding a procedure, as is the case of main verb san and auxiliary san.

Various guidelines have been proposed by different authors for determining the extent to which a form is grammaticalized. Lehmann $(1985,1995)$ proposes a set of parameters for assessing the grammaticalization process of a form. They include integrity, paradigmaticity, paradigmatic variability, structural scope, bondedness and syntagmatic variability. Lehmann's parameters, useful as they are, appear to be aptly suited for well established grammatical forms, for example, the development of articles in modern Romance languages. Determining, however, the functional and formal homogeneity of a paradigm involving the auxiliary san may be abortive since there is no such well defined class of auxiliaries in the language.

Thus in examining the extent of grammaticalization of san, I resort to Hopper's (1991) principles of grammaticalization. Hopper's principles are intended to supplement Lehmann's, they are not only intended to help identify grammaticalization at a conspicuously late stage but also even at the outset, where there may be varying phenomena. Hopper's five principles of grammaticalization are layering, divergence, specialization, ${ }^{7}$ persistence and de-categorisation. In the following sub-sections, I take a look at how these principles are applicable to the lexical item under consideration here. I need to mention that I do not intend that each of these principles serves as an independent piece of evidence in favour of the grammaticalization process. Rather it is a combination of these principles applicable to san which gives an indication of the diachronic development of the auxiliary.

\subsubsection{Layering}

Hopper (op. cit.: 23) describes layering as follows:

(it) refers to the prominent fact that very often more than one technique is available in a language to serve similar or even identical functions. They may be specialised for particular lexical items or simply be recognised as stylistic alternatives.

\footnotetext{
${ }^{7}$ Specialization refers to the fact that different forms with different semantic nuances may have 'specialized' functions, which are conflated as the grammaticalization process proceeds. I do not discuss this particular principle any further since it is not found to be relevant to the forms under investigation, considering the fact that there is no historical evidence to indicate that san and bio had 'specialized' functions during an earlier period.
} 
This phenomenon is evidenced by the existence of san as a companion of a main verb to indicate recurrence and bio, an adverb (discussed in more detail in $\S 4$ ), which performs a similar function. The alternative forms (a) and (b) in (13) could be used without any significant differences in meaning in identical contexts ${ }^{8}$. In such circumstances the choice between san and bio is a matter of stylistic preference.

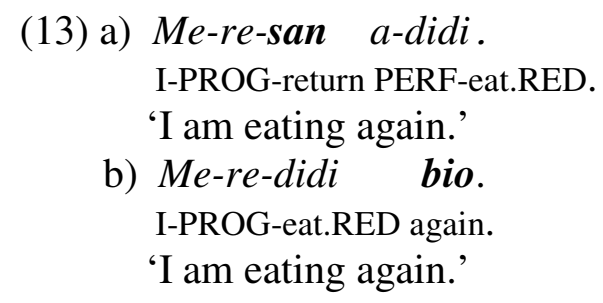

\subsubsection{Divergence}

The grammaticalization principle of divergence "refers to the fact that when a lexical form undergoes grammaticalization, for example to an auxiliary, clitic or affix, the original form may remain as an autonomous lexical element...... The Principle of Divergence results in pairs or multiples of forms having a common etymology, but diverging functionally. The grammaticized form may be phonologically identical with the autonomous lexical form......". (Hopper 1991: 24)

This situation is identified in Akan, with san existing as a full lexical verb (as illustrated in (8) repeated here as (14) for convenience); at the same time we find a phonologically identical form which is always found in the company of a main verb as in (15). So what we find is a grammaticalised auxiliary form and an autonomous lexical verb existing side by side. As a result there are two lexical items which are identical in form, and they have a common etymology in as far as the meanings they convey are concerned. However, one functions as a lexical verb with an encoded conceptual meaning, while the other has a procedural function, indicating that the lexical verb(s) it accompanies is to be interpreted recurrently.

(14) Kofi re-ko Kumase.o-bE-san .

Kofi PROG-go Kumasi. He-FUT-return.

'Kofi is going to Kumasi. He will return (today).'

(15) Yaa san ko-o fie no mu.

Yaa return go-COMPL house DEF inside.

'Yaa went back into the house.'

This kind of situation, where there exist two homophones, one as part of a lexical category and another in a grammatical one, is what has been described by Heine and Reh (1984) as 'functional split'.

\footnotetext{
${ }^{8}$ It is worth mentioning that san and bio are not mutually exclusive and can indeed co-occur in a single clause, as in meresan adidi bio (I am eating again). The pragmatic effect of their co-occurrence is an emphasis on the recurrent contextual assumption they both trigger.
} 


\subsubsection{Persistence}

Hopper defines persistence as follows:

when a form undergoes grammaticalization from a lexical to a grammatical function, so long as it is grammatically viable some traces of its original lexical meaning tend to adhere to it, and details of its lexical history may be reflected on constraints on its grammatical distribution. (Hopper 1991: 22)

As has already been mentioned, san has a lexical function when used as a main verb and its lexical meaning is 'to return'. As an auxiliary san has a grammatical use which relevance theorists call procedural. In its grammatical use, san may signal a restorative assumption which can easily be linked to its conceptual, lexical meaning. In addition to this, its use could also lead to a repetitive contextual assumption in certain contexts. So while one aspect of its grammatical usage can be linked to its original lexical meaning, another aspect, its repetitive function, cannot be directly linked to the main verb san. I am not suggesting that auxiliary san is a polysemous lexical item, but each time it is used it gives rise to one of the following two assumptions: That the activity described by the proposition containing san is a repetition of something that also occurred at an earlier time, or that a state, which is the result of an event described, represents a return to an original situation or position. There are two nuances of meaning with one directly linked to its lexical conceptual meaning. In comparison with the other recurrence marker bio discussed in this paper (see §4), san is constrained in its grammatical distribution. It always has to occur accompanied by a main verb, specifically before a main verb. Though bio typically occurs clause finally, it has the syntactic liberty of occurring utterance initially as well.

\subsubsection{De-categorisation}

De-categorisation refers to the phenomenon where

Forms undergoing grammaticalization tend to lose or neutralize the morphological markers and syntactic privileges characteristic of the full categories Noun and Verb..... (Hopper 1991: 22)

This de-categorisation process is evidenced by what appears to be the loss of the completive aspect ${ }^{9}$ marker (COMPL) on san (in its auxiliary use) in Asante and its related dialects. 'Kofi came again' or 'Kofi came back' is rendered as (16a) and not as (16b), where there is an illicit completive aspect marker on both verbs. This is contrary to what normally happens in serial verb constructions in Akan where for such sentences to be grammatical all the verbs in the series are marked for tense/aspect. A departure from this norm, where san has lost some of its verbal inflections, is a clear indication of the grammaticalization process.

(16) a) Kofi san ba-e.

Kofi return come-COMPL.

*b) Kofi san-ee ba-e.

\footnotetext{
${ }^{9}$ The completive aspect is what some authors refer to as past tense; I follow Osam $(1994,2004)$ in this choice of terminology.
} 
Kofi return-COMPL come-COMPL.

The above situation is in contrast to what happens when san is a full lexical verb. In that case it takes all the tense/aspect markers including the completive aspect. Example (17) is an illustration of san taking on the completive aspect in its full lexical verb status:

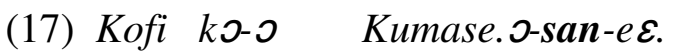

Kofi go-COMPL Kumasi. He-return-COMPL.

'Kofi went to Kumasi. He returned. (i.e. came back the same day)'

Further proof that the loss of the completive aspect marker on auxiliary san is due to a process of grammaticalization is seen in the fact that in the Fante dialect the completive aspect marker remains. While in Asante it is ungrammatical for san to inflect for the completive aspect as in (16b), it is ungrammatical to leave out this marker in Fante. As a result (16a) will be rendered in Fante as (18).

(18) Kofi san-ee ba-e.

Kofi return-COMPL come-COMPL.

Kofi returned.

Thus in the domain of tense/aspect morphology san in Asante has started to lose its full verbal status but this has not yet happened in Fante where san inflects for all the tenses/aspects ${ }^{10}$. The fact that auxiliary san still inflects for some tense/aspect is not surprising. As noted by Heine and Reh (1984), the grammatical form which results through the process of desemanticization remains a "hybrid", at least for a period; for although it has acquired a new status, it may retain some phonological and/or morphosyntactic features from the period of time when it was a lexical form. This paper henceforth focuses on the procedural functions of san.

\subsection{San: Repetitive and restorative}

In this section I distinguish between two 'recurrence' senses of auxiliary san: A restorative sense and a repetitive sense. San as a syntactically independent verb has a restorative $^{11}$ meaning, as illustrated in (8) and (9) above. One would think that this meaning would also dominate in its auxiliary use, but that is not the case of san as an auxiliary is under-specified with respect to whether a given token of the word is to be associated with a restorative or a repetitive pragmatic interpretation.

(19) O-san bisa-a

no nea $\mathcal{E}$-to so abien bio. ${ }^{12}$

He-return ask-COMPL him that it-fall top two again.

${ }^{10}$ San does inflect for COMPL in negative clauses; however the fact that it has lost its COMPL inflection in the unmarked polarity could be taken as part of the initial stage of grammaticalization.

11 The action denoted by the lexical verb san is a turn in some defined space to an original position so a spatial as well as a restorative meaning is embedded in the verb.

${ }^{12}$ This example and the rest in this section, as well as examples (22) to (24) in section 4, are taken from a collection of fables in Akuapem Twi; Ananse Akuamoa (1961, Bureau of Ghana Languages). 
'He asked him again a second time.'

In (19) the assumption which is derived from the use of san in the company of bisa ('ask') is that the action described by the verb was repeated. The explicature of (19) is that the subject referent 0 asked the object referent no a question for the second time. The use of san together with bio guides the reader to the strongly communicated implicated premise that the question being posed had been asked earlier on. Example (19) can only be interpreted as a pure iteration of a linguistic act. The referent of the third person singular pronoun in (19) was asking the interlocutor a question, most probably for the third time, possibly even a fourth time, because of the co-occurrence of san and bio and the number two. A question which had been asked once was being repeated. So san modifying bisa ('ask') is an indication that the asking had been done at least once before and was being done again. The use of san in (20) indicates that the action denoted by the verb phrase woon'atiko ('pushed her') was being repeated.

(20) 0-ma-a no ahina foforo san wo-0 n'atiko se $0-n-k 0$

She-give-COMPL her pot new return push-COMPL POSS-head COMP she-should-go asu no bio. water DEF again.

'She gave her a new pot and insisted that she goes back to fetch water.'

In spite of my English gloss 'goes back to fetch water', I think that the repetitive interpretation (i. e. the action of woo n'atiko being repeated) was intended here, since that appears to be the focus of the narration. (See also Amfo et al. 2004: 15.) In (20) the referent of the first token of no, a little girl, had been sent to fetch water. Unfortunately she fell on her way back and the pot broke. The old lady with whom she was living then sent her a second time with a new pot. Of course going a second time to fetch water means going back to a point/place where she has been in her very recent past, which means restoration, but which is only temporary. Indeed there are several instances like this one, where there seems to be a merger between a restorative and a repetitive sense. Since the girl had been at the riverside once to fetch water, one could say that going there a second time meant restoring her to a former state. However because her original point of departure was the old lady's house, her second visit to the riverside is only a form of 'temporary restoration', as that was not long-lasting. The repetitive reading of san is justified and more salient, because an action of pushing/sending, which appears to be the focal point of the utterance is being repeated. It can be argued that a restorative reading is only accidental in this case.

As in (19), the procedural information provided by san in (20) leads to the assumption that the little girl had been sent once before, in the recent past, to the riverside. This implicated premise provides an input for further deductive inference leading to certain implicated conclusions, such as, 'the girl is tired', 'the old lady is inconsiderate' and 'they needed water badly'.

Of course, there are cases of uses of san where the restorative meaning is quite salient. Consider (21):

(21) Nanso oka a ohene no de ne to ka-a agua no so But touching that king DEF take POSS buttocks touch-COPML chair DEF top na tow a $\mathcal{E}$-tow no kJ-0 sorosan de no be-hwee fam ye 
CONJ throw that it-throw him go-COMPL up return take him MP-fall down is biako.

one.

'However as soon as the king sat down, he was thrown up and brought heavily down again.'

In (21) the king is restored to his former position on the chair after being thrown up in the air, a typical case of san indicating a restoration to a former state. The king starts on a seated position and is returned to that position after a temporary movement.

The conclusion about the uses of san is that it is under-specified in indicating restoration or repetition. Either of these meanings will have to be determined in context. As is characteristic of recurrence markers (See also Fretheim 2001 on English again and Norwegian igjen), they invariably have to work in close tandem with other semantic information in an utterance. In the following section, I turn my attention to the other lexical item under consideration here, bio.

\section{Bio}

\subsection{Repetitive bio}

When bio is used, it probably more often than not gives rise to a repetitive assumption, that is, it leads to the implicated premise that an action indicated by a main verb or series of main verbs is repeated or is to be repeated. This line of interpretation may not be too far fetched; while san can be linked diachronically to a main verb with spatial denotations, bio is a pure temporal marker without a metaphorical link to spatial relations.

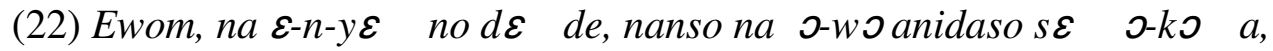
True then it-NEG-be her sweet FM but then she-has hope COMP she-go CM, o-be-hyia okotona w-a-kyere no Nana Aberewa din bio. she-FUT- meet crab CONJ it-CONS-teach her Nana old-lady name again. 'It is true, she was not happy about it, however she had hope that when she goes, she will meet the crab who will tell her the old lady's name again.'

(23) 0-dan n'asae no to-o ho de ne nsa srasra-a he-turn-COMPL POSS-tool DEF put-COMPL there take POSS hand smear.RED-COMPL n'afuru so bisa-a no bio se: "Wu-se nne Ema titiriw abiesa POSS-stomach top ask-COMPL him again COMP "you-say things vital three biara me-p $\boldsymbol{\varepsilon}$. any I-like.

'He put his tool down, moved his hand over his stomach and asked him again: "did you say any three important things that I like?".'

With regard to (22), the crab had mentioned the name of the old lady once before and the referent of $\supset$ hoped that it would mention the name a second time. This explains the modification of the final clause by the adverb bio, an earlier action is expected to be repeated. The use of bio in (23) indicates repetition of a quite unique sort. The 
background to this is that the interlocutor in (23) had just told the speaker that he could ask him any three important things that he desired and his request would be granted. Now to the speaker this sounded too good to be true, so he really wanted to make sure that that was exactly what he heard. What he said was not something that he had asked before but it was something that he had heard before. Bio indicates that the speaker wanted to hear once more what had just been said. It is not simply a repetition of a question which has been asked once before, but it is an echoic metarepresentation (Sperber and Wilson 1986, 1995; Blakemore 1992; Blass 1990; Noh 2000) of something he had just heard from his interlocutor. Bio like san has a repetitive function which indicates to the interlocutor by way of procedural information leading to retrieval of the assumption that the action indicated by the verb phrase to which bio is attached is repeated, or is to be repeated.

\subsection{Restorative bio}

Granted that auxiliary san is the result of a grammaticalization process, which has the lexical verb san ('to return') serving as its diachronic input, it becomes very natural when that word points to a contextual assumption of a return to a former state. But what about bio, whose meaning cannot be traced to any spatially defined notion? Can it also be used to provide procedural information leading to a restorative assumption, that is, a return to a former (usually original) state of affairs? Taking into account data like (24) and (25) the conclusion is that bio is not different from san in this regard.

(24) Abofra yi a-n-ka sE w-a-hwe ase nti 0-re-n-sore bio. Child this COMPL-NEG-say COMP she-PERF-fall down so she-FUT-NEG-get.up again. 'This child did not say that because she has fallen down she will not get up again.'

The assumption communicated in (24) with the aid of bio is that the referent of the NP abofra yi ('this child') is restored to an original position i.e. on her feet, after having fallen from that position, and not the fact that she was going to get up a second time. The assumption that the child was originally in an upright higher position is communicated by an entailment of the complementizer clause, wahwe ase ("she has fallen down'), which is reinforced by the implicated assumption suggested by bio in the following clause. What is communicated explicitly earlier on in the utterance by way of conceptual information, is strengthened procedurally in the second conjunct by means of bio. Example (25) illustrates a similar restorative function of bio.

(25) Yesu wu-e no, ne nansa so, o-sore-e bio.

Jesus die-COMPL DCM, POSS third.day top, he-wake.up-COMPL again.

'When Jesus died, he rose up (again) on the third day.'

Jesus certainly did not wake up a second time or a third time but he woke up to his original state of being alive. The truth-conditions of (25) and (26) are identical. The use of bio in (25) makes the point that Jesus was once alive more salient, which the interlocutor bears in mind in the interpretation process. So like san, bio's pragmatic function here is purely procedural, giving an indication that the state of affairs 
represented by the proposition expressed existed once before as a sort of unmarked situation.

(26) Yesu wu-e no, ne nansa so, O-sore-e. Jesus die-COMPL DCM, POSS third.day top,he-wake.up-COMPL. When Jesus died, he rose up on the third day.

\subsection{Discourse-structural bio}

This section looks at another function of bio, which differs from the functions already discussed in that its scope of operation is at the discourse-structural level. The initial (left-dislocated) position of bio here (as compared to the usual post VP position found in other uses of bio) triggers off this particular function. Its function is similar to English and Norwegian initial position again and igjen, respectively (cf. Fretheim 2001). Bio acts as a sort of paragraph marker within a chapter. It begins a paragraph which introduces a different aspect of an issue that has already been mentioned in the discourse. This use of bio is certainly quite formal and literary. The following excerpt from a book entitled "Mbre mfantsefo si bo apemfo ho ban" ("how Fantes take care of pregnant women') illustrates this use of bio.

(27) Ekyiwadze tsitsir a Akanfo nyina, nkanka Mfantsefo kyir nye de, obaa a woraba abo no bema banyin fofor "afa" no. oye mbusu ma hon beenu no nyina.

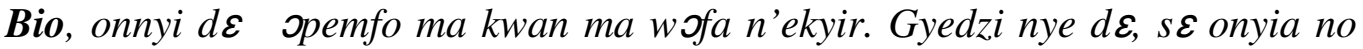

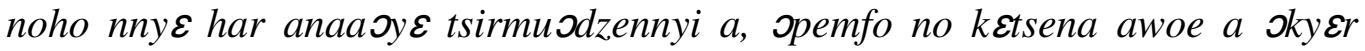
papa.

Bio, onnyi de basia hyE ase fa adze a no kun dze noho ka no, nkanka wo abosoom ebiasa a odzi kan no ти osiande mbasiafo bi wo ho a, bodze bon bi wo honho a annhwe a nna Japon.

'The greatest taboo for Akans especially Fantes, is for the pregnant woman to allow another man (apart from the one who impregnated her) to have sexual relations with her. It is a curse for both of them.

Again, the pregnant woman should not allow anyone to pass behind her. The belief is that if the person is not smart or is a wicked person, the pregnant woman labours for very long when she is due....

Again, the woman should not have sexual relations with the husband at the beginning of the pregnancy, especially during the first three months, because some women have the tendency to miscarry when they do so....

The excerpt in (27) is from a sub-section entitled "The taboos of a pregnant woman". After a brief introduction, the following paragraph talks about the taboos which the 
writer considers most important. The next paragraph which begins with bio is mostly about the public conduct of the pregnant woman. Again, the paragraph which follows, also beginning with bio, shows how the pregnant woman is expected to conduct herself sexually. In the interpretation process, the interlocutor is expected to interpret what follows bio, in the light of what has been said before bio, and together it forms one complete discourse topic. Each paragraph starting with bio is expected to be considered as a new set of rules comparable to the recommendations found in the preceding paragraph. It is thus not surprising that Greenbaum (1969) refers to a similar use of English again as 'additive'.

\section{Conclusion}

This paper has been concerned with the verbal expression of the recurrence of a phenomenon in Akan. Two lexical items which were found to encode recurrence were examined. The auxiliary san appears to be the result of a grammaticalization process, as certain principles of grammaticalization such as layering, divergence, persistence and de-categorisation were found to apply to it, to various extents. Further, it was demonstrated that, in the inferential process, the procedural information san provides leads to the derivation of either a repetitive or a restorative contextual assumption or in certain instances both. Similar assumptions are derived with the use of bio, which is an adverb.

San and bio seem to have the same communicative potential (except for the discourse structural use of bio), in spite of the fact that the lexical meaning of the main verb san, to which auxiliary san is closely associated, is easier to associate with restoration than with repetition. Instead of a lexical differentiation, what we witness is a pattern of functional convergence testifying to the close conceptual relationship between recurrence of the repetitive and of the restorative sort. One significant difference is that bio has other syntactic privileges than san. Whereas san is a close syntactic companion of a (main) lexical verb, bio as an adverb has the freedom to occupy the initial position with its (added) associated pragmatic function discussed in $\$ 4.3$.

\section{List of Abbreviations}

$\mathrm{CM}=$ Conditional marker; $\mathrm{COMP}=\mathrm{Complementiser;} \mathrm{COMPL}=$ Completive aspect; $\mathrm{DEF}=$ Definite article; FM=Focus marker; FUT=Future aspect; $\mathrm{MP}=$ Motional prefix; $\mathrm{NEG}=$ Negation morpheme; $\mathrm{PERF}=$ Perfective aspect; $\mathrm{POSS}=$ Possessive pronoun; PROG=Progressive aspect; RED=Reduplication.

\section{References}

Amfo, N.A.A. (2005) Modal marking in Akan: The case of anka. Journal of Pragmatics 37: 997-1013. 
Amfo, N.A.A., S.A. Boateng, and T. Fretheim (2004) Markers of recurrence in two European and two African Languages. Working papers ISK, 1/2004, Special issue on Contrastive Lexical Pragmatics. Trondheim: NTNU, pp. 1-24.

Andersen, G. (2001) Pragmatic markers and sociolinguistic variation: A relevance-theoretic approach to the language of adolescents. Pragmatics and Beyond, New series, 84. Amsterdam: John Benjamins Publishing Company.

Andersen, G., and T. Fretheim (eds.) (2000) Pragmatic markers and propositional attitude. Pragmatics and Beyond, New series. Amsterdam: John Benjamins Publishing Company.

Blakemore, D. (1987) Semantic constraints on relevance. Oxford: Blackwell Publishing.

Blakemore, D. (1992) Understanding utterances: An introduction to pragmatics. Oxford: Blackwell Publishing.

Blakemore, D. (2002) Relevance and linguistic meaning: The semantics and pragmatics of discourse markers. Cambridge: Cambridge University Press.

Blass, R. (1990) Relevance relations in discourse: A study with special reference to Sissala. Cambridge: Cambridge University Press.

Carston, R. (2002) Thoughts and Utterances: The pragmatics of explicit communication. Oxford: Blackwell Publishing.

Fretheim, T. (2001) A relevance-theoretic account of the way we use and understand the English temporal adverb again and its Norwegian counterpart igjen. Languages in contrast 3.1: 41-94.

Fretheim, T., S.A. Boateng, and I. Vaskó (2003) Then - adverbial pro-form or inference particle? A comparative study of English, Ewe, Hungarian and Norwegian. In K.M. Jaszczolt and K. Turner (eds.), Meaning through language contrast. Vol. 2. Pragmatics and Beyond, New Series. Amsterdam: John Benjamins Publishing Company, pp. 51-74.

Greenbaum, S. (1969) Studies in English adverbial usage. London: Longman.

Grice, H.P. (1975) Logic and conversation. In P. Cole and J. Morgan (eds.), Syntax and Semantics 3: Speech Acts, 41-57.

Heine, B., U. Claudi, and F. Hünnemeyer (1991) Grammaticalization: A conceptual framework. Chicago: University of Chicago Press.

Heine, B., and M. Reh (1984) Grammaticalization and reanalysis in African languages. Hamburg: Helmut Budke Verlag.

Hopper, P.J. (1991) On some principles of grammaticization. In E.C. Traugott and B. Heine (eds.), Approaches to grammaticalization. Volume I. Amsterdam: John Benjamins Publishing Company, pp. 1735 .

Hopper, P.J., and E.C. Traugott (2003) Grammaticalization. $1^{\text {st }}$ edition 1993. Cambridge: Cambridge University Press.

Lakoff, G., and M. Johnson (1980) Metaphors we live by. Chicago: University of Chicago Press.

Lehmann, C. (1985) Grammaticalization: Synchronic variation and diachronic change. Lingua e Stile 20.3: $303-318$.

Lehmann, C. (1995) Thoughts on grammaticalization. Lincom studies in theoretical linguistics. München: Lincom Europa. 
Nicolle, S. (1998) A relevance theory perspective on grammaticalization. Cognitive Linguistics 9.1: 1-35.

Nicolle, S. (2002) Distal aspects in Bantu languages In K.M. Jaszczolt and K. Turner (eds.), Meaning through Language Contrast. Vol. 2. Pragmatics and Beyond, New Series. Amsterdam: John Benjamins Publishing Company, pp. 3-22.

Noh, E-J. (2000) The semantics and pragmatics of metarepresentation in English: A relevance-theoretic account. Pragmatics and Beyond, New Series. Amsterdam: John Benjamins Publishing Company.

Osam, E.K.A. (1994) Aspects of Akan Grammar: A functional perspective. Ph.D. thesis, University of Oregon.

Osam, E.K.A. (2004) The Trondheim Lectures: An introduction to the structure of Akan, its verbal and multiverbal systems. Legon: Department of Linguistics.

Recanati, F. (2004) Literal meaning. Cambridge: Cambridge University Press.

Sperber, D., and D. Wilson (1995) Relevance: Communication and cognition. $2^{\text {nd }}$ edition with a postface. Oxford: Blackwell Publishing. First published 1986.

Wilson, D., and D. Sperber (1993) Linguistic form and relevance. Lingua 90.1-2: 1-25.

Wilson, D., and D. Sperber (2004) Relevance theory. In L. Horn and G. Ward (eds.), The handbook of pragmatics. Oxford: Blackwell Publishing Ltd. 